\title{
IMPACTOS DA ALTERAÇÃO DE PERFIL DO CONSUMO DAS FAMÍLIAS SOBRE O EMPREGO POR OCUPAÇÃO E NÍVEL DE QUALIFICAÇÃO: APLICAÇÃO DE UM MODELO MULTISSETORIAL PARA O BRASIL
}

\author{
Adelar Fochezatto * \\ Carlos Eduardo Lobo e Silva ${ }^{\dagger}$
}

\begin{abstract}
Resumo
Este trabalho analisa os efeitos da alteração do perfil do consumo das famílias, verificada nos últimos anos sobre o mercado de trabalho. Mais especificamente, tem como objetivo: a) verificar as mudanças ocorridas na estrutura da demanda final; e b) dimensionar os efeitos das mudanças na estrutura da demanda final sobre o emprego por atividade econômica, ocupação e qualificação. Para atingir os objetivos, utiliza-se um modelo multissetorial. Os resultados mostram que o crescimento e alteração do padrão dos gastos das famílias impulsionam especialmente a demanda pelo trabalho não qualificado.
\end{abstract}

Palavras-chave: Gastos das famílias; Demanda por mão de obra; Qualificação da mão de obra; Ocupações.

\begin{abstract}
This paper analyzes the effects on the labor market coming from the change of consumption pattern in Brazil observed during the last decade. More specifically, the paper has two objectives: a) identifying the structural changes of the final demand; and $b$ ) measuring the effects of the final-demand structural changes on the number of jobs by economic sectors, occupation, and qualification. To reach those objectives, a multisectoral model was used in this article. The main result shows the finaldemand structural changes boost the demand for unskilled workers.
\end{abstract}

Keywords: Consumption; Labor demand; Labor qualification; Job occupation.

JEL classification: D57, J23, J24, O15.

DOI: http://dx.doi.org/10.1590/1413-8050/ea 122499

\footnotetext{
* Doutor em Economia. Professor Titular da PUCRS. Pesquisador do CNPq. E-mail: adelar@pucrs.br

${ }^{\dagger}$ PhD em Planejamento Regional. Professor da PUCRS. Pesquisador do CNPq. E-mail: carlos.silva@pucrs.br
} 


\section{Introdução}

A economia brasileira tem apresentado níveis de crescimento relativamente elevados na última década em comparação com as duas décadas anteriores. Conforme dados das Contas Nacionais do IBGE, enquanto no período de 1980 a 2002 a taxa geométrica média de crescimento real do Produto Interno Bruto foi de $2,0 \%$ ao ano, no período de 2002 a 2009 a taxa média de crescimento foi de $3,5 \%$ ao ano. O ritmo de crescimento econômico da primeira década do século contou, entre outros fatores, com políticas que favorecem direta ou indiretamente a expansão do consumo das famílias. Bielschowsky (2012) as divide em quatro grupos: rápido aumento da massa salarial; intensificação nas transferências de renda aos mais pobres; estabilidade de preços de bens industriais populares; e forte ampliação do crédito. Adicionalmente, as desonerações setoriais promovidas pelo governo federal e o aumento contínuo da participação da mulher no mercado de trabalho (Jacinto \& Caetano 2011) nos ajudam a entender a expansão do consumo das famílias.

Muitos desses fatores afetam de maneira bastante desigual as diferentes classes de renda da sociedade brasileira. A expansão do crédito, ${ }^{1}$ aliado a um expressivo aumento do acesso à rede bancária (Barone \& Sader 2008, Silva \& Moraes 2013), e o crescimento da transferência de renda - seja por meio de programas como Bolsa Família, seja por impacto do aumento do salário mínimo real sobre as pensões de aposentadoria - são fatores que sugerem uma alteração significativa no padrão de consumo das famílias brasileiras.

No entanto, o objetivo deste artigo não se encerra na análise do padrão de consumo; a motivação do trabalho tem nas alterações de consumo das famílias seu ponto de partida. Retomando uma preocupação apresentada por BresserPereira (2004) sobre um possível ciclo de desenvolvimento concentrador de renda, que vincula o padrão de consumo com a demanda por mão de obra, nosso trabalho ambiciona estimar o impacto que as alterações recentes do padrão de consumo das famílias brasileiras provocam na demanda por mão de obra, classificada aqui quanto às ocupações e à qualificação. Mais especificamente, objetiva-se: a) verificar as mudanças ocorridas na estrutura da demanda final no Brasil e b) dimensionar os efeitos das mudanças na estrutura da demanda final sobre o emprego por atividade econômica, por ocupação e por qualificação. Para atingir o objetivo proposto, é utilizado um modelo multissetorial.

Os dados utilizados para aplicar o modelo são os da nova Matriz de Insumo Produto (MIP) - 2005 e das contas nacionais; os dados da Pesquisa de Orçamentos Familiares (POF) de 2002-2003 e de 2008-2009, ambas do IBGE; além da Relação Anual de Informações Sociais (RAIS) de 2008, disponíveis no Ministério do Trabalho e Emprego. Com os dados da MIP e das contas nacionais é elaborada uma matriz de contabilidade social atualizada para o Brasil e, com os dados da POF, elabora-se uma matriz de consumo setorial das famílias por classe de renda. Os dados da RAIS são usados para desagregar o emprego por ocupações e por qualificação. Para a aplicação do modelo, faz-se ainda a compatibilização setorial das informações entre os setores da RAIS, da POF e do Sistema de Contas Nacionais.

\footnotetext{
${ }^{1}$ As operações de crédito em relação ao PIB brasileiro passaram de 24,2\% em março de 2004 para 48,5\% em outubro de 2011 citepGaleano2011, com impulso especialmente significativo no segmento pessoas físicas, que saltou de um total correspondente a 5,6\% do PIB em 2004 para 14,9\% no final de 2009 (Torres 2010).
} 
Não parece haver razão para acreditar em um retrocesso quanto às políticas de apoio ao fortalecimento do mercado interno, especialmente em relação àquelas que têm efeitos diversos para diferentes classes de renda. Portanto, entender como e em que magnitude esse novo perfil de consumo impacta o mercado de trabalho constitui um passo relevante para a compreensão mais ampla sobre tendências, oportunidades e dificuldades recentes da economia brasileira. Além disso, os resultados obtidos com o método usado neste trabalho podem ajudar a identificar alguns desafios para a qualificação da força de trabalho no Brasil e auxiliar no desenho de políticas que possam promover um crescimento econômico com melhoria da equidade e com aumento da competitividade.

Os estudos que usam a metodologia adotada neste trabalho em geral procuram estabelecer relações estruturais entre a composição da demanda final, a estrutura setorial da produção, o perfil de remunerações dos fatores de produção e a distribuição da renda entre grupos de famílias. Essas dimensões econômicas são intermediadas por um conjunto de relações formando um fluxo circular da renda. Nesse fluxo, não há um ponto inicial e cada uma das suas partes interfere sobre as demais. Os trabalhos pioneiros são Pyatt \& Round (1977, 1979), Stone (1985), Pyatt (1988), Thorbecke (1995), Pyatt (2001) entre outros. Em geral, a hipótese central desses trabalhos é de que o perfil da distribuição da renda, medidos pelo padrão de consumo, tem diferentes efeitos sobre os setores produtivos, influenciando a estrutura produtiva da economia.

Cruyce \& Wera (2007) utilizam uma matriz de insumo-produto da Bélgica de 2000 e 2002 para estimar os multiplicadores de emprego por nível de educação, idade, sexo e por atividade econômica. Os autores concluem que existe uma diferença significativa ente os setores em termos de impactos diretos, indiretos e induzidos sobre o trabalho, desagregado pelas características citadas acima. Por exemplo, através dos efeitos indiretos e induzidos, um setor que demanda emprego de baixa qualificação pode ocasionar aumentos importantes na demanda de emprego qualificado.

Entre os trabalhos aplicados para a economia brasileira destacam-se Bonelli \& Cunha $(1981,1982,1983)$, os quais, em três artigos diferentes, utilizaram modelos alternativos de insumo-produto para analisar a reação da produção setorial a diferentes hipóteses de distribuição de renda e do consumo entre 1970 e 1975.

Entre os estudos mais recentes, Guilhoto et al. (1996) analisaram as estruturas de produção, consumo e distribuição de renda no Brasil em 1975 e 1980, através das matrizes ajustadas de insumo-produto para esses anos. Seus resultados indicam que o polo dinâmico da economia se encontra nos consumidores da classe de renda entre 5 e 20 salários mínimos. Há, também, o trabalho de Cavalcanti (1997), que analisou os impactos de mudanças na distribuição setorial da renda sobre a distribuição funcional da renda. Seus resultados indicam que a estrutura produtiva em vigor propicia uma canalização da renda adicional em favor da classe dos rentistas em prejuízo dos assalariados. Ele conclui, também, que os resultados são muito diferentes entre os setores em função das suas ligações intersetoriais, dos seus coeficientes de consumo e de renda. Por fim, Fochezatto (2011), utilizando dados da POF 2002-03, analisa os efeitos de diferentes estruturas de demanda final sobre a distribuição de renda entre grupos de famílias. Seus resultados mostram que um aumento relativo do consumo das famílias mais pobres não garante uma melhoria na distribuição de renda. 
A proposta deste trabalho segue a linha metodológica dos trabalhos acima, especialmente Cruyce \& Wera (2007) e Fochezatto (2011), embora com uma perspectiva temática um pouco diferente. A pergunta central do presente artigo é a seguinte: mudanças no padrão do consumo e, por consequência, na produção dos setores, influenciam o emprego em quais setores, ocupações e níveis de qualificação? O marco lógico tem as seguintes etapas: políticas governamentais e dinâmicas socioeconômicas alteram a estrutura da demanda final, a qual afeta diferentemente a produção dos setores. Os setores possuem diferentes tecnologias de produção e, portanto, geram diferentes impactos sobre o emprego, ocupações e qualificação.

\section{Metodologia}

A apresentação da metodologia está dividida em duas partes. Inicialmente, o modelo proposto é detalhado, vinculando os passos da sua construção aos objetivos do trabalho. Em seguida, apresenta-se o tratamento dos dados de forma mais detalhada, identificando as estratégias adotadas e hipóteses assumidas.

\subsection{Construção do Modelo}

As alterações na demanda, no perfil produtivo e na estrutura de rendimentos da economia influenciam vários mercados simultaneamente. Para analisar seus efeitos, os modelos multissetoriais são instrumentos adequados porque eles capturam as principais interações entre os diferentes mercados existentes no sistema econômico.

A matriz de insumo-produto é uma representação estática da estrutura econômica de uma economia em um determinado período de tempo. Ela mostra as relações intersetoriais, a demanda final dos setores, o valor adicionado das atividades produtivas e os impostos indiretos, capturando, assim, a interdependência entre os mercados de fatores e de produtos. As transações são organizadas de maneira consistente, de modo a igualar receitas e despesas para cada agente econômico do sistema. As linhas da matriz mostram a demanda total do produto de cada setor, a qual é igual à soma da demanda intermediária e da demanda final (equação 1). As colunas mostram que a produção bruta de cada setor é igual ao consumo intermediário mais os fatores primários ou valor adicionado (equação 2). Para cada setor da economia, se cumpre que a sua produção bruta é igual à sua demanda total (equação 3). Em termos agregados, a soma do valor adicionado dos setores fornece a renda agregada da economia e a soma da demanda final dos setores resulta no dispêndio agregado (equação 4). Em termos formais:

$$
\begin{gathered}
X_{i}=\sum_{j=1}^{n} X_{i j}+\sum_{s=1}^{S} Y_{i s} \\
X_{j}=\sum_{i=1}^{n} X_{i j}+\sum_{r=1}^{R} V_{r j} \\
\sum_{j=1}^{n} X_{i j}+\sum_{s=1}^{S} Y_{i s}=\sum_{i=1}^{n} X_{i j}+\sum_{r=1}^{R} V_{r j}
\end{gathered}
$$




$$
\sum_{i=1}^{n} \sum_{s=1}^{S} Y_{i s}=\sum_{j=1}^{n} \sum_{r=1}^{R} V_{r j}
$$

onde: $X_{i}$ é a demanda total do produto do setor $i ; X_{i j}$ é a demanda intermediária do produto do setor $i$ por parte do setor $j ; Y_{i s}$ é a demanda final do produto do setor $i$ na categoria $s$; $X_{j}$ é a produção bruta do setor $j ; V_{r j}$ é o fator primário $\mathrm{r}$ no valor adicionado do setor $j ; i, j=1,2, \ldots, n$ são os setores produtivos da economia; $s=1,2, \ldots, S$ são as categorias de demanda final; e $r=1,2, \ldots, R$ são os fatores primários que compõem o valor adicionado.

No modelo de insumo-produto, supõe-se que os coeficientes técnicos de produção são fixos e mostram a quantidade do produto do setor $i$ requerida para produzir uma unidade de produto do setor $j$. Os requerimentos de fatores primários também têm uma relação fixa e definem a quantidade do fator primário $r$ requerida para produzir uma unidade de produto total no setor $j$. Assim:

$$
\begin{aligned}
& a_{i j}=\frac{X_{i j}}{X_{j}} \text { ou } a_{i j} X_{j}=X_{i j} \\
& b_{r j}=\frac{V_{r j}}{X_{j}} \text { ou } b_{r j} X_{j}=V_{r j}
\end{aligned}
$$

onde: $a_{i j}$ representa os coeficientes técnicos de produção; e $b_{r j}$ representa os coeficientes dos fatores primários.

No modelo aberto de insumo-produto, todas as categorias de demanda final são consideradas exógenas. Partindo das equações (1) e (5), e usando a notação matricial, a solução desse modelo é definida pela seguinte expressão:

$$
X=(I-A)^{-1} Y
$$

onde: $X$ é um vetor coluna $(n \times 1)$ de produção total dos setores; $I$ é uma matriz identidade $(n \times n) ; A$ é a matriz de coeficientes técnicos $(n x n)$; e $Y$ é um vetor coluna $(n \times 1)$, representando o somatório das categorias de demanda final para o produto de cada setor. Os coeficientes da matriz inversa $(I-A)^{-1}$ são chamados de requerimentos diretos e indiretos de produção.

Além dos requerimentos de produção, é possível definir os requerimentos de fatores primários. Combinando a equação (6) na forma matricial com a equação (7) resulta na seguinte expressão de demanda de fatores primários:

$$
V=B X \text { ou } V=B(I-A)^{-1} Y
$$

onde: $V$ é um vetor indicando a demanda de um determinado fator primário em cada setor econômico $(n \times 1)$; $B$ é uma matriz diagonal dos coeficientes de um determinado fator primário $(n \times n)$. $A$ matriz $B(I-A)^{-1}$ é chamada de matriz de requerimentos diretos e indiretos de fatores primários.

Neste trabalho, foi utilizado um modelo de insumo-produto fechado em que o consumo das famílias foi considerado endógeno. ${ }^{2}$ Substituindo a equação (5) na equação (1), esta equação, na forma matricial, pode ser escrita conforme a equação (9). Esta, por sua vez, com a separação do consumo das

\footnotetext{
${ }^{2}$ Essa transformação do modelo aberto para o fechado baseia-se em Najberg \& Vieira (1996) e Najberg \& Ikeda (1999). Vale lembrar que, nesse caso, a alteração da demanda tem impacto direto, indireto e pelo efeito renda.
} 
famílias das demais categorias de demanda final, pode ser reescrita de acordo com a equação (10):

$$
\begin{gathered}
A X+Y=X \\
A X+C+Y^{\prime}=X
\end{gathered}
$$

em que $Y$ é um vetor da soma dos componentes da demanda final (nx1); $C$ é o vetor de consumo das famílias $(n \times 1)$; e $Y^{\prime}$ é um vetor da soma das demais categorias de demanda final $(n \times 1)$.

Considerando-se que o consumo do produto de cada setor da economia seja endógeno e uma função linear da renda, então ele pode ser expresso conforme a equação (11). Sabendo-se que a renda agregada (valor adicionado) é igual ao dispêndio agregado (equação 4) e que a renda setorial representa uma fração do valor bruto da produção do setor, esta equação pode ser reescrita de acordo com a equação (12). A equação (13) nada mais é do que a equação (12) escrita no formato matricial:

$$
\begin{gathered}
X_{i}=d_{i} Y \\
C_{i}=d_{i} \sum_{j=1}^{n} r_{j} X_{j} \\
C=D R X
\end{gathered}
$$

onde $C_{i}$ é o consumo do produto do setor $i ; d_{i}$ é um vetor de propensão média a consumir do produto $i$; $r_{j}$ é o coeficiente de valor adicionado do setor $j$.

Substituindo a equação (13) na equação (10) pode-se definir a solução do modelo fechado para a produção dos setores (equação 14) e para a demanda de fatores primários (equação 15):

$$
\begin{aligned}
& X=(I-A-D R)^{-1} Y 1 \\
& V=B(I-A-D R)^{-1} Y^{\prime}
\end{aligned}
$$

Este trabalho calculou os impactos sobre o emprego usando o modelo da equação (16). As variações na demanda final em cada setor da matriz foram definidas pela diferença entre a Pesquisa de Orçamento Familiar (POF) do ano 2008-09 e da POF de 2002-03. A partir dos resultados sobre o emprego total dos setores, foi feita a desagregação para emprego por qualificação (grau de instrução) e por ocupações, usando as equações (17) e (18).

$$
\begin{gathered}
\frac{\Delta V}{\Delta Y^{\prime}}=B(I-A-D R)^{-1} \\
V_{q j}=h_{q j} \Delta V_{j} \\
V_{o j}=h_{o j} \Delta V_{j}
\end{gathered}
$$

onde: $\Delta V$ é o impacto sobre o emprego do setor $j$, decorrente de uma alteração na demanda final $\Delta Y^{\prime} ; V_{q j}$ é a variação do emprego da qualificação q no setor $j$; 
$h_{q j}$ é a participação do emprego da qualificação q no setor $j ; \Delta V_{j}$ é a variação do emprego total no setor $j ; V_{o j}$ é a variação do emprego da ocupação o no setor $j$; e $h_{o j}$ é a participação do emprego da ocupação o no setor $j$.

Em linhas gerais, a mudança de perfil dos gastos das famílias será captada pela Pesquisa de Orçamento Familiar dos anos 2002-03 e 2008-09. Essa variação entra como um choque na matriz de insumo-produto que, a partir dos seus multiplicadores setoriais de produção e dos índices também setoriais do número de trabalhadores gerado por unidade monetária produzida, fornece o impacto na demanda por mão de obra. Finalmente, a RAIS informa as ocupações e qualificações do trabalho de cada setor produtivo. Portanto, a metodologia parte da identificação da mudança de perfil dos gastos das famílias, estima os efeitos sobre a produção e, finalmente, estima como a alteração na produção afeta a demanda por trabalho em termos de ocupações e de qualificações (mensurada neste trabalho pelo nível de escolaridade).

A Figura 1 mostra de forma esquematizada a estratégia empírica que será seguida na elaboração da pesquisa.

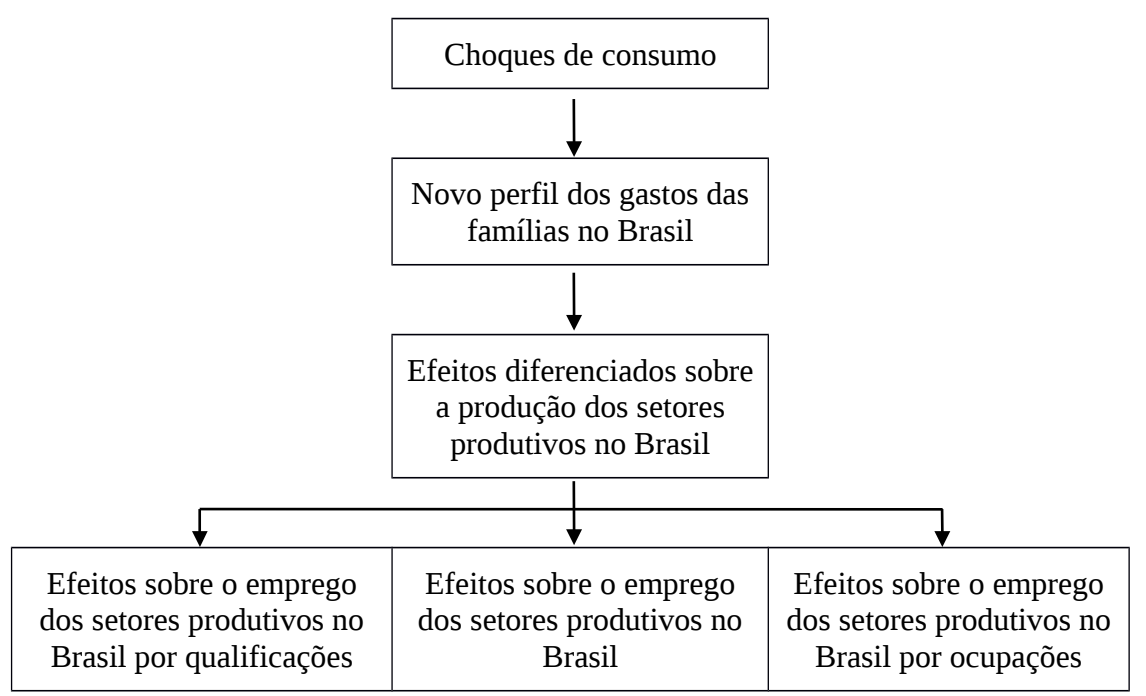

Fonte: Elaboração dos autores.

Figura 1: Fluxograma com os procedimentos operacionais da execução da pesquisa

A utilização de diferentes fontes de dados exigiu um esforço de compatibilização e ajustes que são descritos na seção abaixo.

\subsection{O tratamento dos dados}

Os dados utilizados da POF foram relativos aos períodos 2002-2003 e 20082009. Os valores do POF de 2002-03 foram corrigidos pelo IPCA, considerando a variação do nível geral de preços de dezembro de 2002 a dezembro de 2008. Em seguida, calculou-se a variação dos gastos entre os dois períodos.

A próxima tarefa foi compatibilizar os produtos de consumo da POF com os setores da matriz insumo-produto de 2005 com 55 produtos, que foi feita a partir da análise da descrição dos setores. Três aspectos merecem menção. 
Os gastos com alimentação da POF foram examinados em detalhes a partir da tabela que traz a distribuição das despesas mensal familiar com alimentação. Assim, com base na maior desagregação apresentada na tabela da POF, o montante total de alimentação foi distribuído entre os três setores da matriz — agricultura $(12,7 \%)$, alimentos e bebidas $(67,6 \%)$ e serviços de alimentação e alojamento $(19,7 \%)$.

Vale dizer ainda que em alguns casos o consumo da POF incluía mais de um setor. Especialmente na linha "outros" de cada área. Por exemplo, Serviços e Taxas incluem como subprodutos energia elétrica, gás, água, esgoto, telefone fixo, telefone celular, pacote de telefone, TV e outros. Enquanto os quatro primeiros pertencem ao setor 0401 - Eletricidade e gás, água, esgoto e limpeza urbana; os demais ligados à telefonia e internet pertencem ao setor 0801 - Serviços de Informação. Assim, a linha "Outros" foi distribuída pelos dois setores com participações iguais.

Finalmente, um ponto relevante do procedimento adotado diz respeito aos valores das duas linhas relativas ao "Aumento do ativo": imóvel (aquisição) e imóvel (reforma). A soma das variações de aquisição e reforma foi considerada como variação do setor de construção. Entretanto, considerando a matriz insumo-produto, nota-se que as famílias não consumem nada do setor de construção. Isso se dá pelo fato das contas nacionais considerarem os gastos das famílias em construção e reforma de imóvel como parte da formação bruta de capital, constituindo-se como parte do investimento. Dessa forma, apesar dos gastos das famílias na construção e reforma de imóvel não serem considerados consumo pelas contas nacionais, eles impactam diretamente o setor de construção. Por essa razão, os valores do item "Aumento do ativo" da POF foi puxado na matriz de insumo-produto para a coluna de demanda final das famílias e para a linha relativa ao setor de construção. Em outras palavras, consideram-se aqui os gastos relativos à construção e reforma de imóveis como demanda final das famílias pelo setor da construção.

Superados os cálculos e compatibilizações da POF, passou-se à construção dos coeficientes técnicos da matriz insumo-produto. O primeiro passo foi construir um modelo completo, que levasse em conta não apenas as relações intersetoriais, mas que também considerasse o valor adicionado da produção que impulsiona o consumo das famílias que, por sua vez, retorna como aumento da demanda. Para tanto, um vetor coluna de consumo das famílias foi construído a partir das contas nacionais e inserido na matriz (incluindo no vetor o valor do aumento de ativo na linha relativa ao setor de construção civil), além da linha de valor adicionado que também passou a fazer parte da matriz completa.

A partir do choque de demanda, a matriz dos coeficientes fornece a variação do valor bruto da produção. Dividindo o valor total da produção de 2005 pelo número de trabalhadores chega-se ao índice do valor bruto da produção setorial para cada trabalhador empregado no setor em questão. Como esses índices são utilizados para estimar variações de emprego em função da variação da demanda a preços de 2008-09, é necessário corrigir os valores, o que foi feito utilizando-se mais uma vez o IPCA.

O impacto da demanda no valor bruto da produção e os índices mencionados acima nos permitem identificar o número de postos de trabalho gerados / destruídos em função da variação da demanda final. De posse desses valores, a Relação Anual de Informações Sociais (RAIS) possibilita a decomposição do número de trabalhadores de cada setor em diferentes classes de ocupação e 
qualificação, que é definida aqui pelo nível de escolaridade.

\section{Resultados}

Os principais resultados apresentados neste artigo podem ser divididos em três grupos. Os resultados iniciais mostram o impacto da variação dos gastos das famílias entre 2002-03 e 2008-09 na demanda por mão de obra. Mais especificamente, os resultados trazem o impacto total desagregado em nove ocupações e em onze níveis de escolaridades, tratados, a partir daqui, como qualificações.

O segundo grupo de resultados recupera a estrutura da mão de obra empregada no Brasil em 2008, tanto em termos de ocupações quanto em qualificação, e a compara com a distribuição dos impactos causados pela variação dos gastos das famílias. Essa comparação enriquece a análise, pois permite identificar em quanto o aumento dos gastos das famílias durante o período estudado alterou a estrutura vigente e as características da mão de obra da economia brasileira.

Finalmente, o terceiro grupo de resultados analisa os efeitos da mudança do padrão de consumo na demanda por mão de obra. Para tanto, os resultados encontrados inicialmente são comparados com as alterações na demanda por mão de obra que ocorreriam, caso o padrão dos gastos das famílias de 200809 fosse o mesmo do padrão de 2002-03. Assim, considera-se a variação total ocorrida em termos absolutos, mas a distribui pelos itens de despesa conforme o padrão vigente em 2002-03. Esse exercício ressalta a relevância da mudança de perfil de gastos na demanda por mão de obra, não apenas em termos de números de postos de trabalho, mas também no tocante à sua distribuição em termos de ocupação e qualificação.

O impacto total no número de empregos em razão do aumento de consumo das famílias entre os períodos 2002-03 e 2008-90 foi de 15.866 .069 postos de trabalho (última coluna dos anexos 1 e 2). Esse valor corresponde a 17,91\% do total da mão de obra empregada em 2002. ${ }^{3}$ A Tabela A.1 do Apêndice mostra a distribuição dos quase 16 milhões de empregos gerados nas nove ocupações definidas pela RAIS, e traz ainda o impacto por setor e por ocupações; enquanto, na Tabela A.2 do Apêndice, observa-se a distribuição por qualificação total e o impacto por setor e por qualificação.

Quanto às ocupações, destaque especial deve ser dado ao setor de trabalhadores da produção de bens e serviços industriais $I(27,5 \%)$, seguido pelos trabalhadores do serviço do comércio $(19,5 \%)$ e pelos trabalhadores agropecuários, florestais e da pesca $(18,5 \%)$. Os trabalhadores do grupo da produção de bens e serviços industriais I "desempenham trabalhos 'artesanais', entendidos como os trabalhadores que conhecem e trabalham em todas as fases do processo de produção, independentemente de usar equipamentos rudimentares ou sofisticados" (Classificação Brasileira de Ocupações: CBO, 2010, p.5). Para diferenciá-los dos trabalhadores do grupo da produção de bens e serviços industriais $I I$, estes últimos são os operadores de máquinas. Finalmente, os trabalhadores do grupo de serviços de reparação e manutenção são aqueles de nível elementar de competência (não qualificados) (CBO, 2010).

\footnotetext{
${ }^{3}$ Para manter a consistência dos resultados, o total de emprego deve vir da matriz insumoproduto. Como não há disponível a matriz para o ano de 2002, o total de empregos foi calculado a partir de uma média ponderada dos totais das matrizes de 2000 e 2005.
} 
Em relação à qualificação, a variação dos gastos das famílias tem impactado de forma mais preponderante a demanda por trabalhadores com nível médio completo $(34,3 \%)$. Em seguida, aparece o grupo fundamental completo $(16,7 \%)$. Chama a atenção o pequeno impacto na demanda por trabalhadores com nível superior completo $(6,2 \%)$ e a quase inexistente por trabalhadores com pós-graduação: o aumento da demanda pelas duas categorias - com mestrado e com doutorado - somadas não chegam a 0,2\% do impacto total.

As Figuras 2 e 3 comparam a distribuição do impacto total com a estrutura de produção existente em 2008. Em ocupações (Figura 2), apesar do impacto percentual da demanda pelos trabalhadores agropecuários, florestais e da pesca ser apenas o terceiro mais significativo, como visto na Tabela A.1, quando comparado com a estrutura produtiva, a diferença passa a ser a mais significativa, pois somente $4 \%$ do total dos trabalhadores estão locados nestas atividades. A disparidade pode ser explicada pelo fato do item alimentação ter participação expressiva nas despesas totais das famílias. Mais especificamente, os gastos com alimentação representaram $16 \%$ da despesa total e $19,7 \%$ da despesa de consumo das famílias.

Vale mencionar ainda que as duas ocupações que são proporcionalmente mais demandadas do que as respectivas participações no total da mão de obra são os grupos relativos aos bens e serviços industriais $I$ - aqueles que não operam máquinas - e serviços de manutenção e reparação, composto, segundo a própria definição da CBO (2010), por trabalhadores de baixa qualificação. Certamente, o importante aumento dos gastos na construção civil explica ao menos parte destes resultados. A participação da variação líquida de ativos via aquisição de imóvel em relação às despesas totais saltou de 2,77\% em 200203 para 3,96\% seis anos depois.

Já com relação às qualificações, as conclusões são bastante claras: não considerando os trabalhadores com pós-graduação - uma vez que tanto a participação desse grupo na estrutura produtiva quanto o impacto gerado sobre eles são pouco significativos - a distribuição do aumento de demanda está mais concentrada nos grupos de baixa qualificação do que a distribuição dos trabalhadores na estrutura produtiva. Dos nove grupos restantes, isso acontece nos seis grupos de menor qualificação e o contrário se verifica nos grupos de trabalhadores com médio completo, superior incompleto e superior completo.

Novas comparações são reportadas nas Figuras 4 e 45. O impacto calculado inicialmente em termos de qualificação e ocupação é agora comparado com o impacto que teria sido gerado, caso o padrão de despesa (distribuição entre os itens de despesa) verificado em 2002-03 se mantivesse até 2008-09. Assim, para calcular este efeito hipotético, distribui-se o a variação total observada entre 2002-03 e 2008-09, obedecendo à participação de cada item nos gastos totais de 2002-03. A diferença entre o impacto de demanda por trabalho inicialmente calculado e este hipotético, que "congela" o padrão dos gastos das famílias de 2002-03, é apresentada pelas Figuras 4 e 5. Na Figura 4, os valores são distribuídos por ocupação, enquanto a Figura 5 mostra a diferença em termos de qualificação da mão de obra.

Como primeiro resultado, chama a atenção o fato de que, tivesse o padrão de gastos das famílias se mantido ao longo do período estudado, a variação total de gastos ocorrida teria gerado 698.788 empregos a mais do que os 15.866.069 estimados neste trabalho, que considera a variação real de cada item da despesa.

Analisando a Figura 4, percebe-se que o grupo 'trabalhadores agropecuá- 


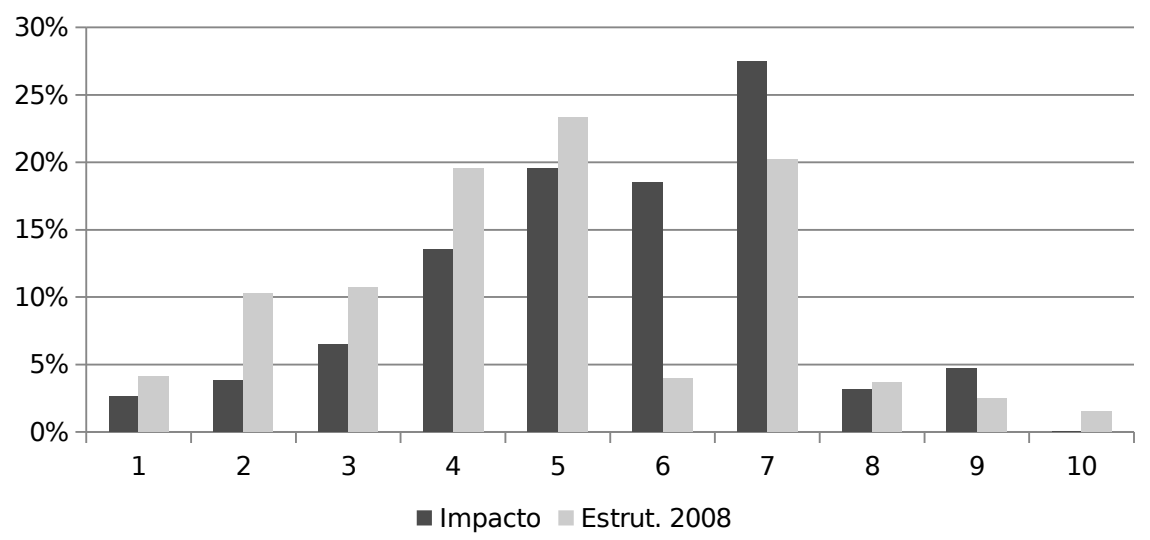

Fonte: Resultados da pesquisa.

${ }^{1}$ Membros superiores do poder público, dirigentes de organizações de interesse público.

2 Profissionais das ciências e das artes.

3 Técnicos de nível médio.

${ }^{4}$ Trabalhadores de serviços administrativos.

${ }^{5}$ Trabalhadores dos serviços, vendedores do comércio em lojas e mercados.

${ }^{6}$ Trabalhadores agropecuários, florestais e da pesca.

${ }^{7}$ Trabalhadores da produção de bens e serviços industriais I.

${ }^{8}$ Trabalhadores da produção de bens e serviços industriais II.

${ }^{9}$ Trabalhadores em serviços de reparação e manutenção.

10 Não classificado.

Figura 2: Impacto da variação dos gastos das famílias na demanda por trabalho comparado com a estrutura de produção - por ocupações.

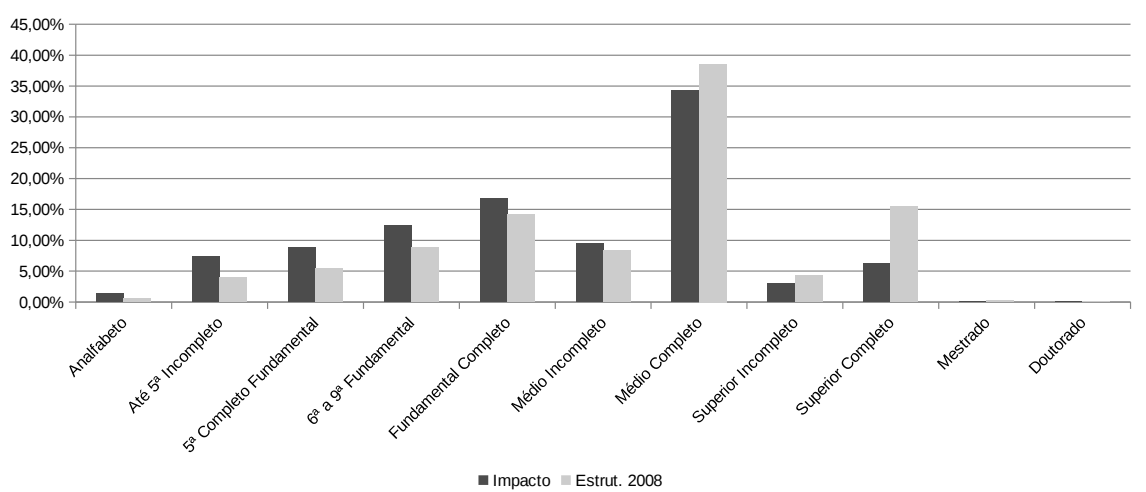

Fonte: Resultados da pesquisa.

Figura 3: Impacto da variação dos gastos das famílias na demanda por trabalho comparado com a estrutura de produção - por qualificação. 
rios, florestais e da pesca' apresenta a maior diferença, que ultrapassa os 600 mil empregos. O novo padrão de gasto das famílias demanda, proporcionalmente, menos trabalhadores desse grupo de trabalhadores do que demandava o padrão de 2002-03. Uma explicação para essa diferença parece ser a participação do item 'alimentos' nas despesas de consumo, que passou de 20,7\% para $19,7 \%$. À primeira vista, essa redução pode parecer pequena demais para explicar tal diferença, mas um ponto percentual na participação dos gastos totais de consumo altera significativamente os valores absolutos: enquanto a variação real dos gastos em alimentos apresentou ligeira redução entre 200203 e 2008-09, para manter os 20,7\% de participação de 2002-03, ela teria que aumentar 4,7\% durante o mesmo período. O padrão de gastos de 2008-09 gera maior demanda apenas para os trabalhadores de bens e serviços industriais $I$ e reparo e manutenção (Na Figura 4, grupos VII e IX).

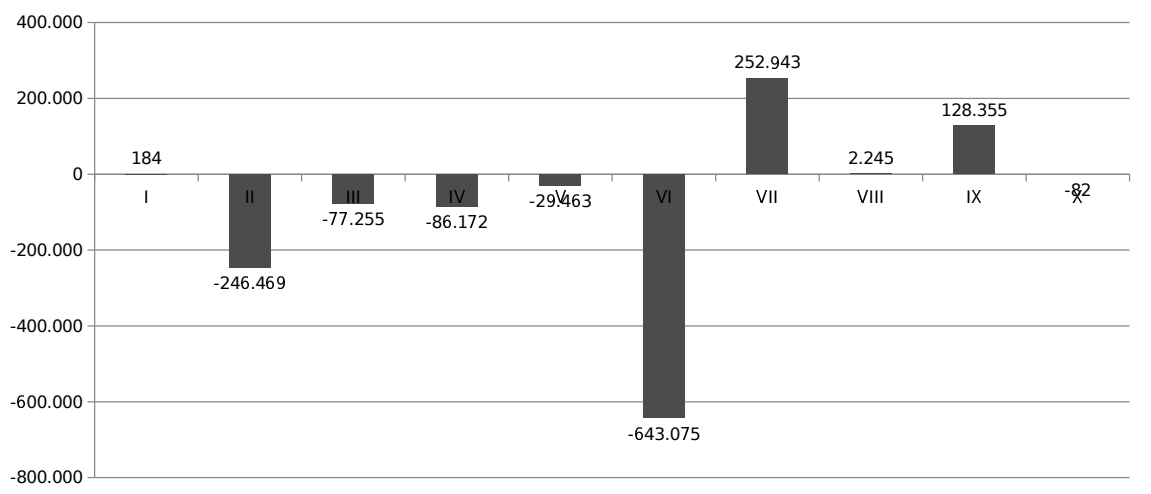

Fonte: Resultados da pesquisa.

${ }^{I}$ Membros superiores do poder público, dirigentes de organizações de interesse público.

II Profissionais das ciências e das artes.

III Técnicos de nível médio.

IV Trabalhadores de serviços administrativos.

$V$ Trabalhadores dos serviços, vendedores do comércio em lojas e mercados.

VI Trabalhadores agropecuários, florestais e da pesca.

VII Trabalhadores da produção de bens e serviços industriais I.

VIII Trabalhadores da produção de bens e serviços industriais II.

IX Trabalhadores em serviços de reparação e manutenção.

$X$ Não classificado.

Figura 4: Impactos comparados: padrão de gastos das famílias de 2008 menos padrão de gastos das famílias de 2002 - por ocupação.

Finalmente, a Figura 5 mostra a mesma comparação para as qualificações. Com exceção do grupo de trabalhadores com ensino médio, todos os demais são menos demandados em função da mudança no padrão de gastos. Considerando todos os grupos, a demanda por trabalhadores com ensino superior completo é a que mais reduz em função da mudança de padrão de gastos.

Portanto, se a expansão dos gastos das famílias tende a demandar trabalho de baixa qualificação e, especialmente, daqueles ligados à fabricação de bens e serviços industriais e de reparação e manutenção, essa tendência se fortalece com a mudança de padrão ocorrida durante o período estudado. 


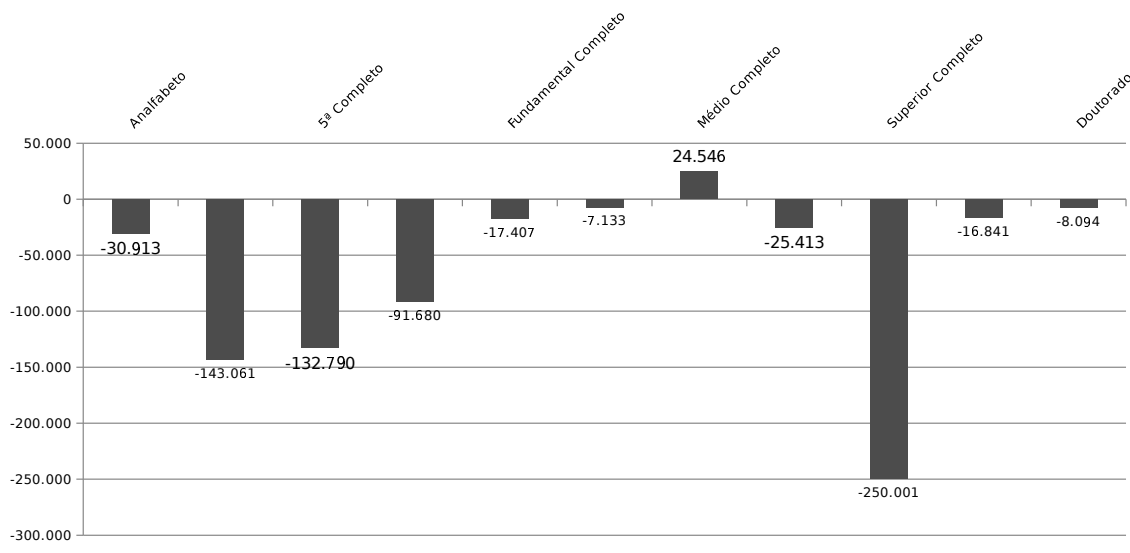

Fonte: Resultados da pesquisa.

Figura 5: Impactos comparados: padrão de gastos das famílias de 2008 menos padrão de gastos das famílias de 2002 — por qualificação

\section{Considerações Finais}

A partir da metodologia empregada, pode-se chegar a algumas conclusões importantes a respeito dos efeitos do crescimento dos gastos das famílias sobre a demanda por mão de obra. A primeira delas é relativa ao aumento de demanda pelo trabalho não qualificado. Especialmente quando a distribuição do impacto é comparada com a estrutura produtiva, percebe-se que os grupos de baixa qualificação - até ensino médio incompleto - recebem um percentual do impacto total maior que a participação do grupo na estrutura produtiva (embora o Grupo com ensino médio completo receba o maior impacto absoluto); enquanto os grupos de alta qualificação recebem um impacto proporcionalmente menor do que as respectivas participações no total da mão de obra empregada.

No caso das ocupações, a importância crescente da construção civil e a participação declinante dos alimentos no total das despesas parecem explicar os dois resultados mais expressivos: (1) o forte impacto na demanda pelos trabalhadores relativos aos bens e serviços industriais I e (2) o crescimento menor da demanda pelos trabalhadores agropecuários, florestais e da pesca do que teria sido caso não houvesse mudança no padrão dos gastos das famílias.

Portanto, em linhas gerais, a alteração ocorrida no padrão de consumo das famílias no Brasil tem impactado de forma mais significativa o emprego de baixa qualificação, especialmente ocupações ligadas à produção industrial.

\section{Referências Bibliográficas}

Barone, F. M. \& Sader, E. (2008), 'Acesso ao crédito no brasil: evolução e perspectivas', Revista de Administração Pública 42(6), 1249-1267.

Bielschowsky, R. (2012), 'Estratégia de desenvolvimento e as três frentes de expansão no brasil: um desenho conceitual', Economia e Sociedade 21(número especial), 729-747.

Bonelli, R. \& Cunha, P. V. (1981), 'Crescimento econômico, padrão do consumo e distribuição da renda no brasil: uma abordagem multissetorial para 
o período 1970/75', Pesquisa e Planejamento Econômico 11(3), 703-756. Rio de Janeiro.

Bonelli, R. \& Cunha, P. V. (1982), 'Mudanças nas estruturas de produção, renda e consumo, e crescimento econômico no brasil no período 1970/75', Pesquisa e Planejamento Econômico 12(3), 807-850. Rio de Janeiro.

Bonelli, R. \& Cunha, P. V. (1983), 'Distribuição de renda e padrões de crescimento: um modelo dinâmico da economia brasileira', Pesquisa e Planejamento Econômico 13(1), 91-154. Rio de Janeiro.

Bresser-Pereira, L. C. (2004), Desenvolvimento e crise no Brasil, Editora 34: São Paulo.

Cavalcanti, J. E. A. (1997), 'Distribuição setorial da renda: Seus efeitos de indução na economia brasileira', Pesquisa e Planejamento Econômico 27(1), 141184.

Cruyce, B. V. \& Wera, J. (2007), Qualitative employment multipliers for belgium, results for 2000 and 2002, in '16th International Input-Output Conference in Istanbul', Turquia.

Fochezatto, A. (2011), 'Estrutura da demanda final e distribuição de renda no brasil: Uma abordagem multissetorial utilizando uma matriz de contabilidade social', Economia (ANPEC) 12, 111-130. Brasília.

Guilhoto, J. J. M., Conceição, P. H. Z. \& Crocomo, F. C. (1996), 'Estrutura de produção, consumo e distribuição de renda na economia brasileira: 1975 e 1980 comparados', Economia \& Empresa 3.

Jacinto, P. A. \& Caetano, S. M. (2011), 'Os efeitos trabalhador adicional e desalento: uma análise para as regiões metropolitanas do nordeste', Revista Econômica do Nordeste 42(2), 351-364.

Najberg, S. \& Ikeda, M. (1999), Modelo de geração de emprego: metodologia e resultados, Texto para Discussão 72, BNDES, Rio de Janeiro.

Najberg, S. \& Vieira, S. P. (1996), 'Modelos de geração de emprego aplicados à economia brasileira: 1985/95', Revista do BNDES 3(5), 63-86. Rio de Janeiro.

Pyatt, G. (1988), 'A sam approach to modelling', Journal of Policy Modeling 10(3), 327-352.

Pyatt, G. (2001), 'Some early multiplier models of the relationship between income distribution and production structure', Economic Systems Research 13(2), 139-164.

Pyatt, G. \& Round, J. I. (1977), 'Social accounting matrices for development planning', Review of Income and Wealth Series 23(4), 339-364.

Pyatt, G. \& Round, J. I. (1979), 'Accounting and fixed price multipliers in a sam framework', The Economic Journal 89, 850-873.

Silva, T. L. F. \& Moraes, G. I. (2013), 'Determinantes da demanda por crédito pessoa física - recursos livres, no período 2004-2011, em estados selecionados', Pesquisa E Debate 23(2), 327-344. 
Stone, J. R. N. (1985), The disaggregation of the household sector in the national accounts, in G. Pyatt \& J. I. E. Round, eds, 'Social Accounting Matrices: A Basis for Planning', The World Bank, Washington D.C, pp. 145-185.

Thorbecke, E. (1995), Intersectoral linkages and their impact on rural poverty alleviation: A social accounting approach, Technical report, United Nations Development Organisation (UNIDO), Vienna.

Torres, E. T. (2010), Crédito cresce forte em 2009, apesar da crise internacional. visão do desenvolvimento, Technical Report 80, BNDES.

\section{Apêndice A}


Tabela A.1: Número de postos de trabalho gerados por setor e por qualificação

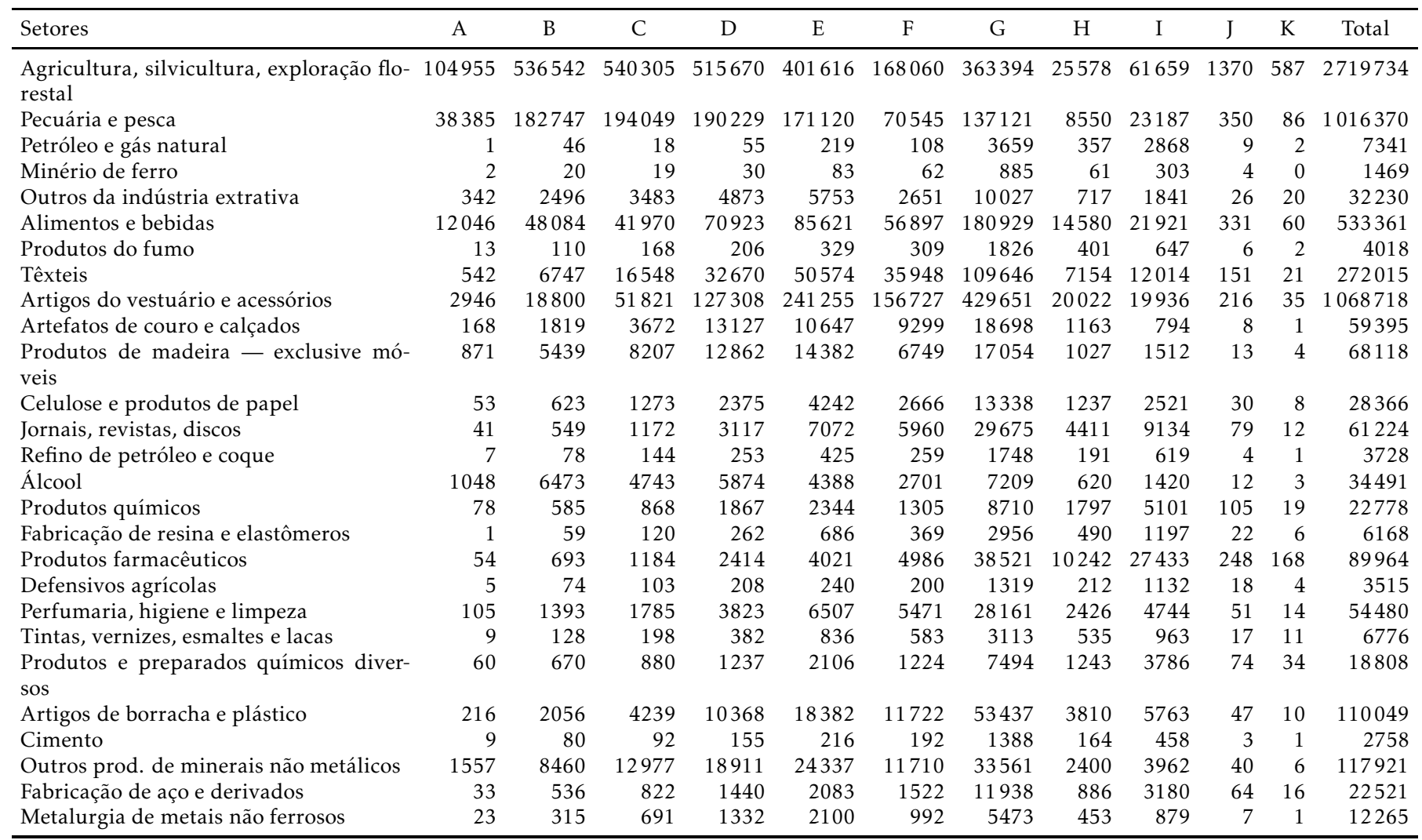

$\mathrm{A}=$ Analfabeto, $\mathrm{B}=$ Até $5^{\mathrm{a}}$ Incompleto, $\mathrm{C}=5^{\mathrm{a}}$ Completo Fundamental, $\mathrm{D}=6^{\mathrm{a}}$ a $9^{\mathrm{a}}$ Fundamental, $\mathrm{E}=$ Fundamental Completo, $\mathrm{F}=\mathrm{Médio}$

Incompleto, $\mathrm{G}=$ Médio Completo, $\mathrm{H}$ = Superior Incompleto, $\mathrm{I}=$ Superior Completo, $\mathrm{J}=$ Mestrado, $\mathrm{K}=$ Doutorado.

Fonte: Resultados da pesquisa. 
Tabela A.1: Número de postos de trabalho gerados por setor e por qualificação (continuação)

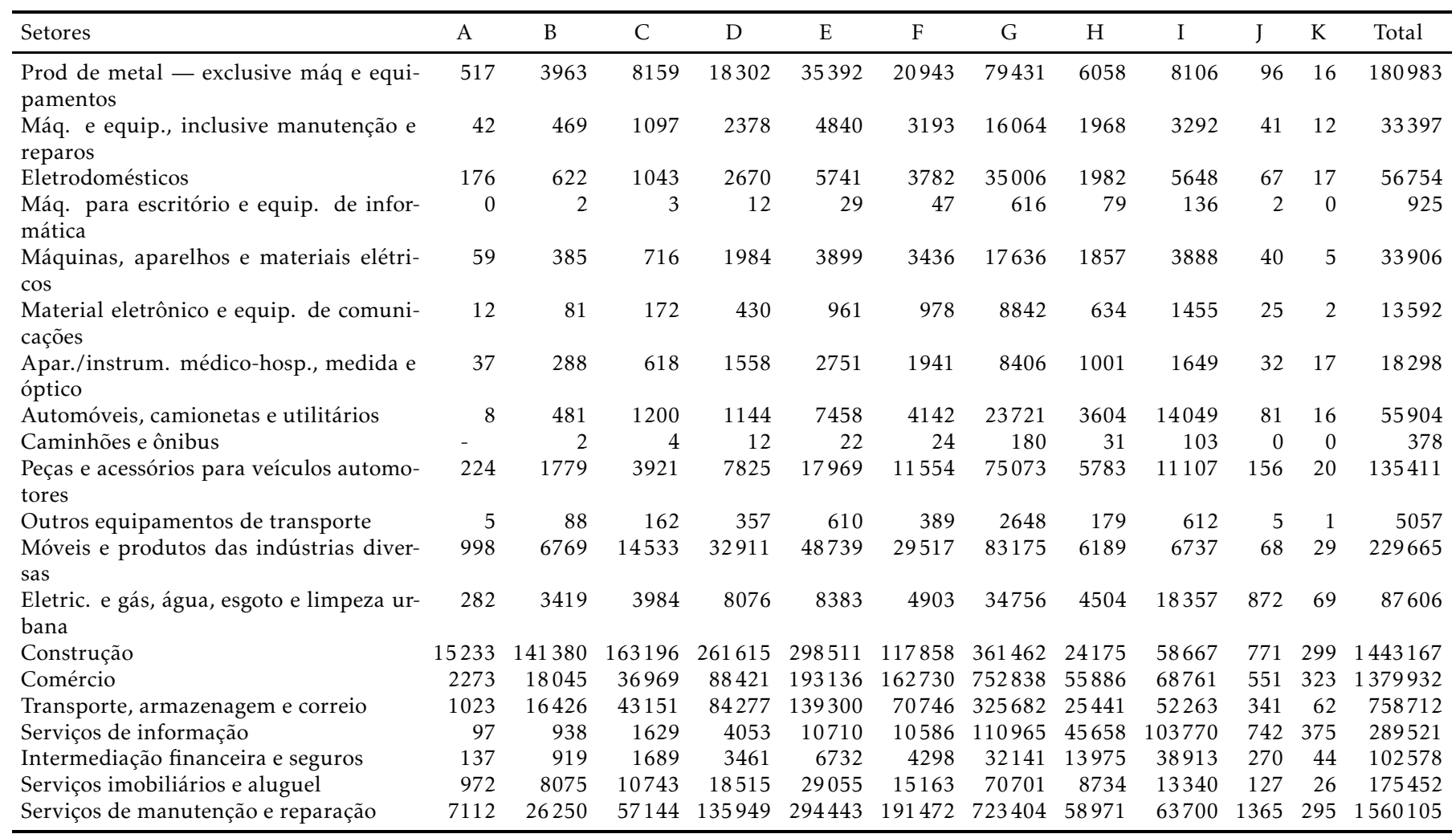

$\mathrm{A}=$ Analfabeto, B = Até $5^{\mathrm{a}}$ Incompleto, $\mathrm{C}=5^{\mathrm{a}}$ Completo Fundamental, $\mathrm{D}=6^{\mathrm{a}}$ a $9^{\mathrm{a}}$ Fundamental, $\mathrm{E}=$ Fundamental Completo, $\mathrm{F}=\mathrm{Mé}$ dio Incompleto, $\mathrm{G}=$ Médio Completo, $\mathrm{H}=$ Superior Incompleto, $\mathrm{I}=$ Superior Completo, $\mathrm{J}=$ Mestrado, $\mathrm{K}=$ Doutorado.

Fonte: Resultados da pesquisa. 


\begin{tabular}{|c|c|c|c|c|c|c|c|c|c|c|c|c|}
\hline Setores & A & B & $\mathrm{C}$ & $\mathrm{D}$ & $\mathrm{E}$ & $\mathrm{F}$ & G & $\mathrm{H}$ & I & $\mathrm{J}$ & $\mathrm{K}$ & Total \\
\hline $\begin{array}{l}\text { Serviços de alojamento e alimen- } \\
\text { tação }\end{array}$ & 3644 & 17662 & 43493 & 87506 & 184370 & 111873 & 317950 & 12497 & 20406 & 226 & 35 & 799663 \\
\hline Serviços prestados às empresas & 1699 & 11695 & 21540 & 42729 & 78472 & 39362 & 272347 & 33947 & 52759 & 862 & 607 & 556020 \\
\hline Educação mercantil & -3 & -23 & -33 & -65 & -105 & -69 & -582 & -145 & -1209 & -95 & -48 & -2375 \\
\hline Saúde mercantil & 386 & 3354 & 6337 & 11683 & 23705 & 18403 & 175104 & 13088 & 62274 & 386 & 201 & 314921 \\
\hline Outros serviços & 11199 & 77647 & 91689 & 132333 & 198852 & 119487 & 389753 & 46355 & 160708 & 3790 & 971 & 1232786 \\
\hline Educação pública & 5 & 40 & 47 & 58 & 140 & 48 & 454 & 55 & 463 & 6 & 1 & 1316 \\
\hline Saúde pública & 0 & 1 & 1 & 1 & 3 & 1 & 9 & 1 & 10 & 0 & 0 & 27 \\
\hline $\begin{array}{l}\text { Administração pública e seguri- } \\
\text { dade social }\end{array}$ & 81 & 715 & 853 & 1040 & 2533 & 873 & 8209 & 986 & 8365 & 115 & 14 & 23786 \\
\hline Total & 209788 & 1167094 & 1405611 & 1971206 & 2658235 & 1506897 & 5446922 & 484220 & 997303 & 14247 & 4541 & 15866069 \\
\hline Percentual do total & $1,32 \%$ & $7,36 \%$ & $8,86 \%$ & $12,42 \%$ & $16,75 \%$ & $9,50 \%$ & $34,33 \%$ & $3,05 \%$ & $6,29 \%$ & $0,09 \%$ & $0,03 \%$ & $100,00 \%$ \\
\hline
\end{tabular}

$\mathrm{A}=$ Analfabeto, $\mathrm{B}=$ Até $5^{\mathrm{a}}$ Incompleto, $\mathrm{C}=5^{\mathrm{a}}$ Completo Fundamental, $\mathrm{D}=6^{\mathrm{a}}$ a $9^{\mathrm{a}}$ Fundamental, $\mathrm{E}=$ Fundamental Completo, $\mathrm{F}=$ Médio Incompleto, $\mathrm{G}$

= Médio Completo, $\mathrm{H}=$ Superior Incompleto, $\mathrm{I}=$ Superior Completo, $\mathrm{J}=$ Mestrado, $\mathrm{K}=$ Doutorado.

Fonte: Resultados da pesquisa. 
Tabela A.2: Número de postos de trabalho gerados por setor e por ocupação

\begin{tabular}{|c|c|c|c|c|c|c|c|c|c|c|c|}
\hline Setores & Ocup1 & Ocup2 & Ocup3 & Ocup4 & Ocup5 & Ocup6 & Ocup7 & Ocup8 & Ocup9 & NC & Total \\
\hline $\begin{array}{l}\text { Agricultura, silvicultura, exploração flo- } \\
\text { restal }\end{array}$ & 38092 & 31389 & 60912 & 114347 & 121109 & 2026399 & 249725 & 23732 & 53736 & 293 & 2719734 \\
\hline Pecuária e pesca & 20482 & 14102 & 18461 & 41957 & 59649 & 775080 & 59487 & 18650 & 8457 & 46 & 1016370 \\
\hline Petróleo e gás natural & 134 & 2068 & 1712 & 755 & 155 & 6 & 1308 & 1016 & 186 & 0 & 7341 \\
\hline Minério de ferro & 53 & 145 & 316 & 81 & 21 & 1 & 528 & 19 & 304 & - & 1469 \\
\hline Outros da indústria extrativa & 751 & 995 & 2015 & 2889 & 2369 & 389 & 18707 & 1553 & 2559 & 4 & 32230 \\
\hline Alimentos e bebidas & 13347 & 8810 & 25421 & 51598 & 89037 & 70071 & 106791 & 153649 & 14609 & 28 & 533361 \\
\hline Produtos do fumo & 274 & 251 & 826 & 410 & 93 & 94 & 785 & 902 & 383 & - & 4018 \\
\hline Têxteis & 5695 & 5068 & 20993 & 26243 & 17605 & 836 & 170891 & 12321 & 12350 & 15 & 272015 \\
\hline Artigos do vestuário e acessórios & 23980 & 11705 & 35848 & 83510 & 95254 & 639 & 801340 & 8280 & 8131 & 30 & 1068718 \\
\hline Artefatos de couro e calçados & 743 & 421 & 1656 & 3214 & 1240 & 55 & 50083 & 1467 & 516 & 1 & 59395 \\
\hline $\begin{array}{l}\text { Produtos de madeira - exclusive mó- } \\
\text { veis }\end{array}$ & 1751 & 708 & 1863 & 5253 & 3468 & 3505 & 47532 & 2411 & 1624 & 3 & 68118 \\
\hline Celulose e produtos de papel & 861 & 908 & 2620 & 2907 & 1353 & 357 & 10594 & 7550 & 1208 & 7 & 28366 \\
\hline Jornais, revistas, discos & 2400 & 7173 & 5408 & 13283 & 5617 & 43 & 25517 & 1173 & 604 & 6 & 61224 \\
\hline Refino de petróleo e coque & 85 & 301 & 555 & 401 & 294 & 35 & 1075 & 836 & 146 & 1 & 3728 \\
\hline Álcool & 322 & 679 & 1590 & 2137 & 1516 & 16177 & 6598 & 3295 & 2177 & - & 34491 \\
\hline Produtos químicos & 1515 & 1932 & 3154 & 3534 & 1235 & 452 & 4894 & 4905 & 1157 & - & 22778 \\
\hline Fabricação de resina e elastômeros & 265 & 491 & 1295 & 623 & 167 & 6 & 1331 & 1748 & 241 & 1 & 6168 \\
\hline Produtos farmacêuticos & 5929 & 7605 & 22718 & 12246 & 15705 & 121 & 10382 & 12805 & 2347 & 106 & 89964 \\
\hline Defensivos agrícolas & 307 & 351 & 627 & 364 & 215 & 262 & 643 & 639 & 107 & - & 3515 \\
\hline Perfumaria, higiene e limpeza & 1956 & 1796 & 4575 & 8358 & 8063 & 131 & 19553 & 8180 & 1850 & 16 & 54480 \\
\hline Tintas, vernizes, esmaltes e lacas & 328 & 367 & 1139 & 1141 & 522 & 11 & 1322 & 1806 & 140 & - & 6776 \\
\hline $\begin{array}{l}\text { Produtos e preparados químicos diver- } \\
\text { sos }\end{array}$ & 1123 & 1356 & 2599 & 2667 & 1373 & 461 & 3982 & 4568 & 677 & 1 & 18808 \\
\hline Artigos de borracha e plástico & 2850 & 2313 & 9933 & 11890 & 5761 & 211 & 42987 & 28901 & 5196 & 6 & 110049 \\
\hline Cimento & 105 & 164 & 510 & 351 & 153 & 5 & 790 & 249 & 431 & - & 2758 \\
\hline
\end{tabular}

Ocup. 1 = Membros superiores do poder público, dirigentes de organizações de interesse público, Ocup. 2 = Profissionais das ciências e das artes, Ocup. 3 = Técnicos de nível médio, Ocup. 4 = Trabalhadores de serviços administrativos, Ocup. $5=$ Trabalhadores dos serviços, vendedores do comércio em lojas e mercados, Ocup. $6=$ Trabalhadores agropecuários, florestais e da pesca, Ocup. $7=$ Trabalhadores da produção de bens e serviços industriais I, Ocup. 8 = Trabalhadores da produção de bens e serviços industriais II, Ocup. $9=$ Trabalhadores em serviços de reparação e manutenção, NC = Não Classificado.

Fonte: Resultados da pesquisa. 
Tabela A.2: Número de postos de trabalho gerados por setor e por ocupação (continuação)

\begin{tabular}{|c|c|c|c|c|c|c|c|c|c|c|c|}
\hline Setores & Ocup1 & Ocup2 & Ocup3 & Ocup4 & Ocup5 & Ocup6 & Ocup7 & Ocup8 & Ocup9 & $\mathrm{NC}$ & Total \\
\hline Outros produtos de minerais não metálicos & 2695 & 1766 & 4567 & 9498 & 6906 & 481 & 61951 & 26592 & 3455 & 10 & 117921 \\
\hline Fabricação de aço e derivados & 537 & 1613 & 3658 & 1950 & 693 & 186 & 7268 & 4476 & 2139 & 0 & 22521 \\
\hline Metalurgia de metais não ferrosos & 283 & 391 & 1255 & 870 & 356 & 16 & 6585 & 1714 & 794 & 0 & 12265 \\
\hline $\begin{array}{l}\text { Produtos de metal - exclusive máquinas e } \\
\text { equipamentos }\end{array}$ & 4020 & 3651 & 13765 & 17963 & 8620 & 293 & 113951 & 11018 & 7695 & 6 & 180983 \\
\hline $\begin{array}{l}\text { Máquinas e equipamentos, inclusive manu- } \\
\text { tenção e reparos }\end{array}$ & 1005 & 1423 & 4498 & 3825 & 1585 & 58 & 16615 & 1529 & 2858 & 1 & 33397 \\
\hline Eletrodomésticos & 852 & 2445 & 5070 & 4653 & 2506 & 32 & 35745 & 4269 & 1181 & - & 56754 \\
\hline $\begin{array}{l}\text { Máquinas para escritório e equipamentos } \\
\text { de informática }\end{array}$ & 33 & 74 & 147 & 156 & 46 & 0 & 437 & 18 & 12 & 0 & 925 \\
\hline Máquinas, aparelhos e materiais elétricos & 1042 & 1957 & 4015 & 3546 & 1084 & 20 & 18803 & 2061 & 1375 & 1 & 33906 \\
\hline $\begin{array}{l}\text { Material eletrônico e equipamentos de co- } \\
\text { municações }\end{array}$ & 440 & 821 & 2281 & 1661 & 581 & 10 & 7234 & 296 & 266 & 1 & 13592 \\
\hline $\begin{array}{ll}\text { Aparelhos/instrumentos } & \text { médico- } \\
\text { hospitalar, medida e óptico } & \end{array}$ & 596 & 819 & 2514 & 2442 & 980 & 18 & 9576 & 728 & 624 & 0 & 18298 \\
\hline Automóveis, camionetas e utilitários & 1520 & 5989 & 6053 & 2865 & 909 & - & 33922 & 329 & 4317 & - & 55904 \\
\hline Caminhões e ônibus & 7 & 35 & 69 & 24 & 7 & 0 & 207 & 2 & 28 & - & 378 \\
\hline $\begin{array}{l}\text { Peças e acessórios para veículos automoto- } \\
\text { res }\end{array}$ & 2653 & 5006 & 14223 & 11357 & 2870 & 72 & 83494 & 9450 & 6282 & 4 & 135411 \\
\hline Outros equipamentos de transporte & 114 & 357 & 641 & 465 & 127 & 3 & 2677 & 212 & 463 & 0 & 5057 \\
\hline Móveis e produtos das indústrias diversas & 5900 & 2584 & 8767 & 23275 & 15477 & 544 & 158056 & 11602 & 3443 & 19 & 229665 \\
\hline
\end{tabular}


Tabela A.2: Número de postos de trabalho gerados por setor e por ocupação (continuação)

\begin{tabular}{|c|c|c|c|c|c|c|c|c|c|c|c|}
\hline Setores & Ocup1 & Ocup2 & Ocup3 & Ocup4 & Ocup5 & Ocup6 & Ocup7 & Ocup8 & Ocup9 & $\mathrm{NC}$ & Total \\
\hline $\begin{array}{l}\text { Eletricidade e gás, água, esgoto e lim- } \\
\text { peza urbana }\end{array}$ & 4320 & 9886 & 12049 & 16181 & 13049 & 190 & 19238 & 10004 & 2684 & 5 & 87606 \\
\hline Construção & 16004 & 37151 & 69220 & 111903 & 114685 & 7477 & 1007070 & 11006 & 68552 & 101 & 1443167 \\
\hline Comércio & 78285 & 33942 & 67745 & 332850 & 567768 & 7816 & 199970 & 44263 & 47143 & 150 & 1379932 \\
\hline Transporte, armazenagem e correio & 15361 & 17335 & 50135 & 159312 & 144365 & 5808 & 333566 & 3861 & 28912 & 57 & 758712 \\
\hline Serviços de informação & 15608 & 86778 & 69072 & 82356 & 18040 & 145 & 13731 & 808 & 2960 & 23 & 289521 \\
\hline Intermediação financeira e seguros & 8281 & 12170 & 8589 & 50906 & 15331 & 349 & 5288 & 476 & 1182 & 6 & 102578 \\
\hline Serviços imobiliários e aluguel & 6543 & 6423 & 10902 & 44408 & 40224 & 1753 & 58484 & 980 & 5706 & 29 & 175452 \\
\hline Serviços de manutenção e reparação & 48773 & 44061 & 174134 & 268160 & 264568 & 2891 & 339117 & 12515 & 405646 & 239 & 1560105 \\
\hline Serviços de alojamento e alimentação & 40820 & 7694 & 11013 & 100291 & 582616 & 2539 & 19159 & 30268 & 5146 & 117 & 799663 \\
\hline Serviços prestados às empresas & 9775 & 32617 & 40845 & 170782 & 233460 & 4069 & 49670 & 5331 & 9358 & 113 & 556020 \\
\hline Educação mercantil & -55 & -1168 & -441 & -397 & -255 & -6 & -39 & -4 & -10 & 0 & -2375 \\
\hline Saúde mercantil & 5023 & 51496 & 102722 & 86393 & 59127 & 510 & 6997 & 852 & 1771 & 29 & 314921 \\
\hline Outros serviços & 28538 & 130863 & 113784 & 246034 & 566780 & 11762 & 116913 & 5171 & 12766 & 174 & 1232786 \\
\hline Educação pública & 118 & 308 & 262 & 260 & 214 & 4 & 44 & 3 & 13 & 91 & 1316 \\
\hline Saúde pública & 2 & 6 & 5 & 5 & 4 & 0 & 1 & 0 & 0 & 2 & 27 \\
\hline $\begin{array}{l}\text { Administração pública e seguridade so- } \\
\text { cial }\end{array}$ & 2131 & 5564 & 4733 & 4700 & 3877 & 65 & 799 & 48 & 227 & 1643 & 23786 \\
\hline Total & 424577 & 605155 & 1033042 & 2148856 & 3098573 & 2942452 & 4363376 & 500531 & 746121 & 3386 & 15866069 \\
\hline Percentual do total & $2,68 \%$ & $3,81 \%$ & $6,51 \%$ & $13,54 \%$ & $19,53 \%$ & $18,55 \%$ & $27,50 \%$ & $3,15 \%$ & $4,70 \%$ & $0,02 \%$ & $100,00 \%$ \\
\hline \multicolumn{12}{|c|}{$\begin{array}{l}\text { Ocup. } 1 \text { = Membros superiores do poder publico, dirigentes de organizações de interesse publico, Ocup. } 2=\text { Profissionais das ciências e das artes, } \\
\text { Ocup. } 3 \text { = Técnicos de nível médio, Ocup. } 4=\text { Trabalhadores de serviços administrativos, Ocup. } 5=\text { Trabalhadores dos serviços, vendedores do } \\
\text { comercio em lojas e mercados, Ocup. } 6=\text { Trabalhadores agropecuários, florestais e da pesca, Ocup. } 7=\text { Trabalhadores da produção de bens e serviços } \\
\text { industriais I, Ocup. } 8=\text { Trabalhadores da produção de bens e serviços industriais II, Ocup. } 9=\text { Trabalhadores em serviços de reparação e manutenção, } \\
\text { NC = Não Classificado. }\end{array}$} \\
\hline
\end{tabular}

